\title{
A General Method for Handling Disturbances on Utilities in the Process Industry
}

\author{
Anna Lindholm* Hampus Carlsson ** Charlotta Johnsson* \\ * Department of Automatic Control, Lund University, Sweden \\ (e-mail: anna.lindholm@control.lth.se) \\ ** Perstorp AB, Stenungsund, Sweden
}

\begin{abstract}
Utilities, such as steam or cooling water, have shown to play an important role within the process industry, since a malfunctioning utility is a plant-wide disturbance that can lead to large revenue losses due to reduced production quantities. This work focuses on identifying disturbances on utilities that give economical consequences. Measures of utility availability and area availability are introduced and used for estimating the ratio of disturbances on utilities. A generic method for handling disturbances on utilities is presented, which could be applied using site models of different level of detail. Some modeling approaches for modeling a site are described and the framework of the general method is demonstrated with a case study example at Perstorp AB, Sweden.
\end{abstract}

Keywords: Disturbance localization, process control, plant-wide disturbances, enterprise modeling

\section{INTRODUCTION}

Disturbances is a wide concept and different disturbances have to be handled using different approaches. In this paper, the focus is on identifying plant-wide disturbances on utilities, such as steam or cooling water, and suggesting a general method for improving the availability of a plant by improving the handling of such disturbances. Disturbances can act at different levels, or different time scales, in the plant hierarchy. Here, disturbances on a site/arealevel are considered, which distinguishes this work from other disturbance management strategies. This is further discussed in section 2. Different types of disturbances and causes of disturbances are discussed in section 3 .

In a production plant, plant-wide disturbances often give rise to great economic loss, and the availability of the plant could be significantly improved if these disturbances are handled in an optimal way. In Qin (1998) it is expressed as "one needs to transfer variability from where it hurts to where it does not hurt as much". For disturbances on utilities, which are typically plant-wide disturbances, an example could be to divide the available steam resources during a steam net pressure drop among the areas of the plant such that the revenue loss is minimized. Utilities, and disturbances on utilities, are further discussed in section 4 .

To develop methods for minimizing the effects of disturbances on utilities at an entire site, the flow of utilities at the site, and how the operation of the utilities affect the production, must be modeled. This modeling can be done in different level of detail, giving disturbance management strategies in the corresponding level of detail. Three different modeling approaches for modeling the site structure are suggested in section 5 . The suggestion is to start with the simplest model and step by step enrich the model to capture more of the variability, as suggested in Morris (1967). The objective in this work is not to go into details of the modeling process, but to provide a general framework for handling disturbances on utilities, that can be used for any site model.

Site Stenungsund at Perstorp AB, Sweden, is used as a case study to exemplify the application of the general method to an industrial site. The case study is presented in section 7 .

\section{EQUIPMENT HIERARCHY}

An enterprise contains one or more sites, which in turn consist of one or more areas. Each production area has one or more production units (ISA-95.00.01-2000 (2000)).

The enterprise determines which products to manufacture and at which site they should be produced. At this level, a lot of work has been done within operations research and logistics, for example in Grossmann and Furman (2009), where enterprise-wide optimization within the process industry is discussed.

Production sites are usually geographically grouped. At this level, scheduling and production planning is often performed and concepts of plant-wide control are used. A systematic procedure for plant-wide control structure design is presented in Skogestad (2004).

Areas are usually grouped by their geographic location and their products. Each area produces one or more products, either end products for external sale or intermediates for further use by other areas at the site. At this level in the equipment hierarchy, local optimization methods and 
control structures such as model predictive control are commonly used to maximize the production of an area.

At the lowest level in the equipment hierarchy for continuous operations, the production unit level, tuning methods for the controllers of the production units are often used. In Skogestad (2004) this level corresponds to the regulatory control layer and the supervisory control layer.

At each level in the hierarchy, a flowchart can be made showing the flow of product through the enterprise, site or area. This is illustrated in figure 1. In these flowcharts, the dependence by a site/area/production unit on another site/area/production unit can be seen.

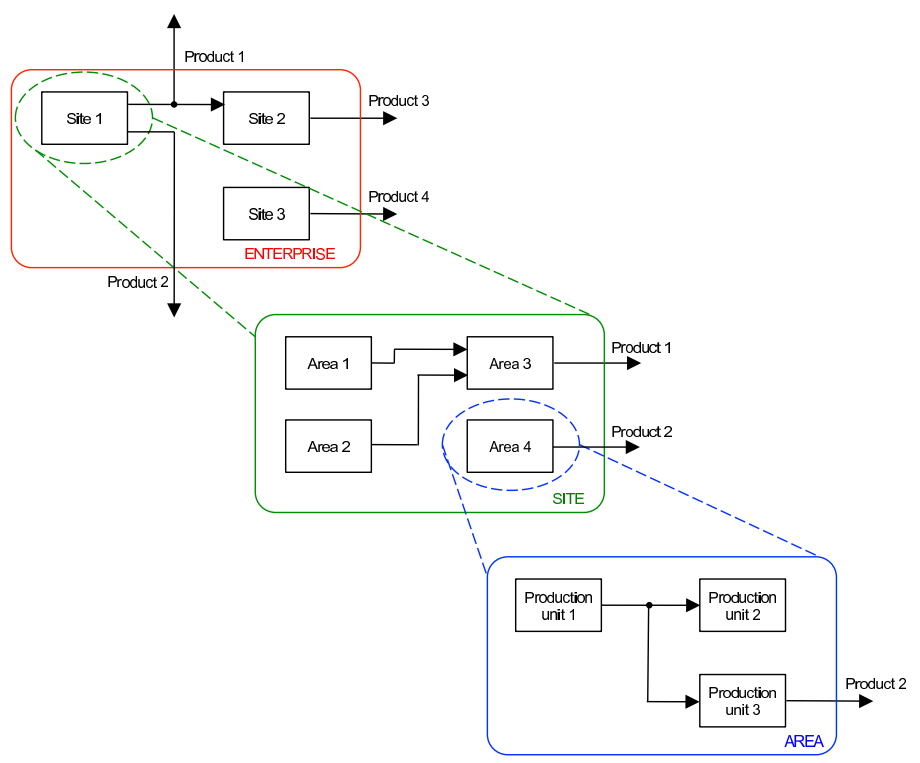

Fig. 1. Flowcharts at different levels in the equipment hierarchy.

This work belongs at the site/area level and does not consider details such as single production units in the areas. The objective is to find methods for minimizing the losses for an entire site due to disturbances on utilities.

\section{DISTURBANCES}

Disturbances at a production site can be divided into two categories:

(1) Local disturbances Disturbances such as a load disturbance in the in- or outflow of a buffer tank. The buffer tank will handle the variations and the disturbance will not cause economic loss for the entire site.

(2) Plant-wide disturbances Disturbances such as a pressure drop in the steam net or variations in cooling water temperature; disturbances that affect the entire site. These disturbances will have a negative impact on the economic performance of the production site (Bauer et al. (2007)).

In this paper, the focus is on plant-wide disturbances.

\subsection{Causes of disturbances}

According to the standard ISA-95.00.01-2000 (2000) the capability of a plant can be divided into three sections;
Personnel, material and equipment. The cause of a disturbance can be categorized accordingly:

(1) Personnel An incorrect action by an operator in the plant or lack of personnel with the correct education may cause a disturbance.

(2) Material Material can be divided into two subcauses:

- Raw materials

- Utilities

Raw materials are materials that are part of the reactions that become the product of the plant whereas utilities are materials that are crucial for plant operation but are not part of the final product. More information on utilities in the process industry is given in section 4 .

(3) Equipment Equipment errors such as a pump failure or a sticky valve may cause disturbances.

An important difference from the standard ISA-95.00.012000 (2000) is that we have made a distinction between raw materials and utilities. In this paper, the focus is on disturbances on utilities.

\subsection{Reducing the effects of disturbances}

What method that can be used for reducing the effects of a disturbance depends on the cause of the disturbance.

(1) Personnel Training of the operators or decision support for exception handling can reduce personnelrelated disturbances (Xia and Rao (1999)).

(2) Material The effects of material-related disturbances can often be reduced by including more redundancy, such as investing in an extra steam boiler or cooling fan. However, these changes are often expensive since they require redesign of the system (Greenberg (1991)). Investing in buffer tanks for raw materials or utilities can also in the same manner reduce the effects of disturbances caused by material. Furthermore, the effects of disturbances on raw materials and utilities might be reduced by dividing the resources of raw materials or utilities in a clever way in the plant, i.e. to transfer the variability to a location where it does as little damage as possible (Qin (1998)). Buffer tanks can also be used for this purpose, since the effects of disturbances caused by material can be reduced by optimal use of the buffer volumes at the occurrence of a disturbance.

(3) Equipment Disturbances caused by equipment can be reduced by proper maintenance, either planned or unplanned. Planned maintenance could be preventive maintenance, scheduled or condition-based, whereas unplanned maintenance is corrective and emergency maintenance only (Williams et al. (1994)). Including more redundancy can also reduce the effects of equipment-related disturbances.

\section{UTILITIES}

In Brennan (1998), some utilities are described. Here, devices for combustion of tail gas and the vacuum system utility have been added to complete the list of common utilities in the process industry. The purpose or use of the utilities are described below. 
- Steam The steam net is commonly used for heating, for example heating of a reactor at start-up, or for supplying energy, for example for distillation or endothermic reactions. There could be several steam nets at the same site, for example one net with highpressure steam and one with low-pressure steam.

- Cooling water The cooling water system is used for cooling at exothermic reactions and in the condensing phase of distillation. Cooling fans, cooling a local cooling coil, are sometimes used for extra cooling in a certain area at the site.

- Electricity Electricity is needed in order for the instruments and pumps to operate. Electricity of different voltages could be required.

- Fuel Fuel, typically gas, oil or coal, may be needed for furnaces, kilns and steam boilers to operate. It may also be required for start-up of certain units or areas.

- Water treatment The Water treatment utility, or effluent treatment, is used for purification of process water $^{1}$, precipitation and ground-water.

- Combustion of tail gas A flare is a safety device used for combustion of tail gas at unforeseen events. There could also be other equipment for combustion of tail gas. These devices are often used for the combustion of tail gas during normal operation, and might be local utilities, i.e. utilities that only affect a single area.

- Nitrogen Nitrogen is needed to maintain pressure in vessels by pushing away oxygen to prevent oxidation.

- Water Feed water, which consists of varying proportion of recovered condensed water (return water) and purified fresh water (make-up water) is needed for the boilers to be able to produce steam. Water is also required for washing and for the fire protection water system.

- Compressed air Compressed air could be both process air and instrument air. Instrument air is needed for the pneumatic instruments to work. Instrument air might be a local utility; e.g. every area has its own instrument air system.

- Vacuum system Vacuum is used to lower the boiling point of a liquid to facilitate distillation and to remove gas produced in reactions.

\subsection{Disturbances on utilities}

Utilities are often such that they do not affect the production as long as they operate within some limits. For example, the cooling water utility does often not affect the production until the temperature of the cooling water is over some temperature limit. One possible way of defining when a utility suffers a disturbance is thereby as when the measurement of a utility parameter, such as temperature or pressure, goes outside a limit at which the poor operation of the utility will have negative consequences for the production at the site. The consequences could be of different severity depending on how large the deviations from the limits are; a really high cooling water temperature could for example affect the production more than just a little too high temperature. The suggestion is to set the limit so that it represents the limit for when maximum

\footnotetext{
1 Process water is water yielded or used in the process.
}

production can no longer be maintained because of poor operation of the utility. Example of such limits for utilities at an industrial site is given in the case study in section 7 .

\subsection{Utility availability}

A key performance index that could be used for determining how often a utility suffers a disturbance is the availability of the utility. The availability of a production unit is according to the standard ISO/WD-22400-2 (2009) the fraction of the production time and the planned busy time, where the planned busy time is the time that the production unit is used for the execution of a manufacturing order. For utilities, the suggestion is to define availability as the fraction of time all utility parameters are inside their limits. This represents the fraction of time when there is a possibility for maximum production, assuming that all utility disturbance limits have been correctly set. Utility availability is easily computed if measurements of all utility parameters are available. Planned stops should not be included in the availability computations.

Utility dependence Some utilities are dependent on other utilities, which may have as consequence that a disturbance on one utility also shows up in the measurements of other utilities. This must be considered when computing the utility availabilities. For example, if feed water is not available, steam could not be produced, and the steam utility could not possibly be available. This should be considered a feed water failure and not a steam failure. An example of a utility dependence flowchart is given in figure 2. These kinds of flowcharts can be used to remove utility dependence from the utility availability computations.

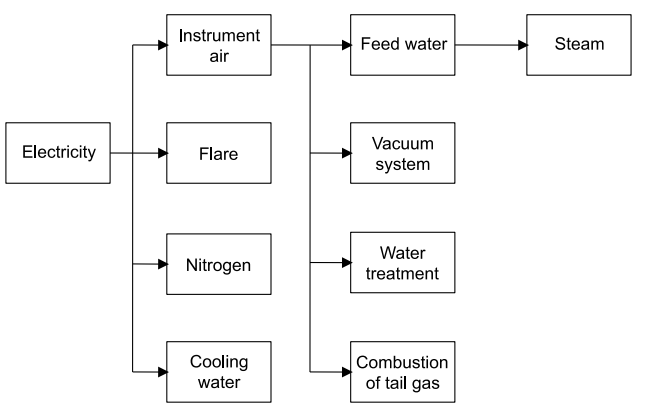

Fig. 2. An example of a utility dependence flowchart.

\subsection{Area availability}

As described in section 2, a site consists of one or more production areas. Every area requires a specific set of utilities in order to operate correctly. Thus, area availability with respect to utilities can be introduced as the fraction of time all utilities needed at the area are available. The area availability should be interpreted as the fraction of time the area can operate at maximum production rate, with respect to utilities. Area availability computed without considering the connection of areas at a site will be denoted direct area availability.

Area dependence If an area is unavailable, this could also affect other areas at the site, since the areas could be dependent on obtaining raw materials from other areas, 
or delivering products to other areas. This dependence can be seen in a flowchart of the site, see section 2. The area dependence can be included in the area availability computations by introducing total area availability, as the fraction of time all utilities required at an area, and all areas that the area is dependent on, are available. This gives a worst-case estimate of the area availabilities, since it does not consider buffer tanks between areas.

\section{MODELING APPROACHES FOR MODELING A PRODUCTION SITE}

For modeling a site with respect to utilities, three different modeling approaches are suggested:

(1) On/off modeling without buffer tanks Utilities and areas are considered to be either operating or not operating, i.e. on/off. An area is available when all its required utilities are available, and unavailable when any of its required utilities are not available. All areas operate at maximum production speed when available, and not at all when not available. It is assumed that there are no buffer tanks between the areas at the site, so that if an area becomes unavailable, its downstream areas with respect to the product flow will immediately also be unavailable.

(2) On/off modeling including buffer tanks The same modeling approach as approach 1, but buffer tanks between areas are also included in the model. The buffer tanks act as delays from when an area becomes unavailable until its downstream areas become unavailable.

(3) Dynamic modeling With dynamic modeling, the possible maximum production rate of an area is determined by the values of the utility parameters for all utilities required by that area.

\section{A GENERAL METHOD FOR HANDLING DISTURBANCES ON UTILITIES}

The general method for handling disturbances on utilities suggested in this paper can be divided into four steps. The first three steps concern computing the revenue loss due to each utility at the site during a certain time period, and the last step concerns minimizing the revenue loss due to future disturbances on utilities. The last two steps of the method requires a model of the site, which could be obtained e.g. by any of the modeling approaches described in section 5 . The accuracy of the strategies for minimizing the revenue loss depends on the level of detail of the model of the site. The best choice of modeling approach depends on how detailed strategies that are required, and how much time and effort that could be used for modeling. One suggestion is to start with a simple modeling approach, and step by step work towards more elaborate models. The general method when using on/off modeling without buffer tanks and on/off modeling including buffer tanks have been investigated in Lindholm et al. (2011) and Lindholm (2011).
The steps of the method, including sub-steps, are listed below.

Step 1: Get information on site-structure and utilities

a) Depict the overall structure of the site

b) List all plant-wide utilities

c) Determine which utilities that are required at each area

d) Draw a utility dependence flowchart

e) Define the disturbance limits for each utility

f) Get relevant measurement data

g) List all planned stops during the time period

Step 2: Compute utility and area availability

a) Compute utility availabilities

b) Compute direct and total area availabilities

Step 3: Compute revenue loss due to disturbances on utilities

a) Select site model

b) Get maximum production rates for each product

c) Get profit margins for each product

d) Compute revenue loss for each product

e) Compute revenue loss due to each utility

Step 4: Minimize the revenue loss due to future disturbances on utilities

In the case study in section 7 , the application of step 1 and 2, which are independent of the choice of site model, to an industrial site is described.

\section{CASE STUDY AT PERSTORP AB}

The case study is performed at Perstorp AB, at their site in Stenungsund, Sweden. Perstorp is a worldwide enterprise that is a world leader in several sectors of the specialty chemicals market. Their products can be found in for example automotive, food, packaging and electronics applications (Perstorp (2011)). At the site in Stenungsund, the main products are aldehydes and organic acids.

\subsection{Step 1: Get information on site-structure and utilities}

Site Stenungsund is one of 13 sites owned by the enterprise Perstorp AB. The site consists of 10 production areas. The products of the 10 areas at the site are here denoted product 1-10 for area 1-10 respectively. A flowchart of the product flow at the site is shown in figure 3 .

Site Stenungsund has all utilities listed in section 4 .

- Steam There are two steam nets at the site, one with high pressure steam, ideally 41 bar, and one with middle pressure steam, ideally 14 bar.

- Cooling water Four areas, area 1, 2, 3 and 7, have cooling fans that cool local cooling coils, in addition to ordinary cooling water.

- Electricity Site Stenungsund uses both $130 \mathrm{kV}$ and $40 \mathrm{kV}$ electricity. A list of disturbances on electricity is provided by the supplier.

- Fuel Fuel is not included as a utility in this case study. However, the effects of fuel being unavailable 


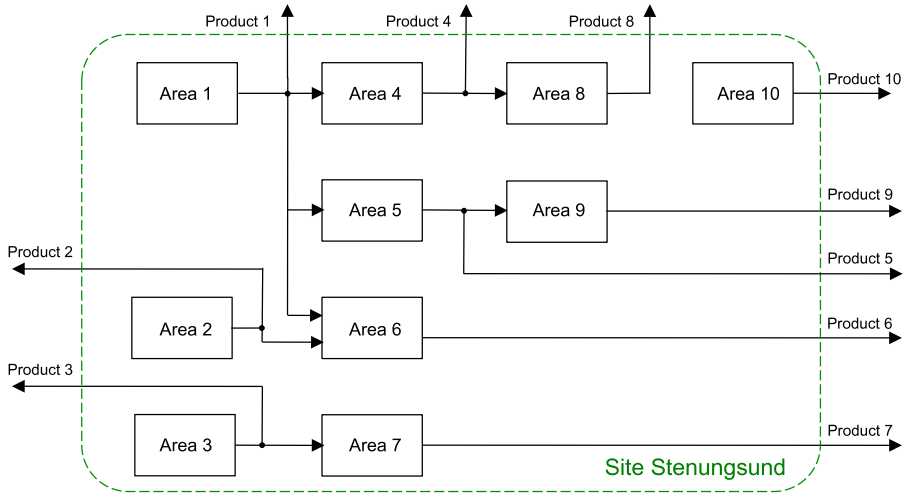

Fig. 3. Flowchart of the product flow at site Stenungsund.

will show up in measurements of other utilities, for example steam.

- Water treatment For the water treatment utility (WTU), there are monthly limits for how large amounts of suspended material (SUSP) and dissolved organic carbon (DOC) that are allowed in the outgoing water, that should not be exceeded. There are also more strict limits for how much of these substances that are allowed in the outgoing water each year. If the yearly limits are exceeded, the site has to be shut down immediately. The monthly and yearly limits are individual for each production site. In this case study, only the yearly limits are considered.

- Combustion of tail gas The site contains a flare and there are also three areas, area 7,8 and 9 , that have devices for local combustion of tail gas at normal operation. However, measurements are only available for the combustion devices at area 7 and area 9 .

- Nitrogen Nitrogen is used to maintain pressure in vessels.

- Water Both feed water, washing water and fire protection water is used at the site, but only feed water will be considered in this case study.

- Compressed air Compressed air could be both process air and instrument air. At site Stenungsund only instrument air is used.

- Vacuum system: The vacuum systems are individual for each area.

A table showing which utilities that are needed at each area is shown in table 1 .

Table 1. Utilities needed at areas at site Stenungsund.

\begin{tabular}{lcccccccccc}
\hline & 1 & 2 & 3 & 4 & 5 & 6 & 7 & 8 & 9 & 10 \\
\hline Steam HP & & & & & & & $\mathrm{x}$ & $\mathrm{x}$ & $\mathrm{x}$ & $\mathrm{x}$ \\
Steam MP & $\mathrm{x}$ & $\mathrm{x}$ & $\mathrm{x}$ & $\mathrm{x}$ & $\mathrm{x}$ & $\mathrm{x}$ & $\mathrm{x}$ & & $\mathrm{x}$ & \\
Cooling water & $\mathrm{x}$ & $\mathrm{x}$ & $\mathrm{x}$ & $\mathrm{x}$ & $\mathrm{x}$ & $\mathrm{x}$ & $\mathrm{x}$ & $\mathrm{x}$ & $\mathrm{x}$ & $\mathrm{x}$ \\
Cooling fans & $\mathrm{x}$ & $\mathrm{x}$ & $\mathrm{x}$ & & & & $\mathrm{x}$ & & & \\
Electricity & $\mathrm{x}$ & $\mathrm{x}$ & $\mathrm{x}$ & $\mathrm{x}$ & $\mathrm{x}$ & $\mathrm{x}$ & $\mathrm{x}$ & $\mathrm{x}$ & $\mathrm{x}$ & $\mathrm{x}$ \\
WTU & $\mathrm{x}$ & $\mathrm{x}$ & $\mathrm{x}$ & $\mathrm{x}$ & $\mathrm{x}$ & $\mathrm{x}$ & & $\mathrm{x}$ & $\mathrm{x}$ & \\
Flare & $\mathrm{x}$ & $\mathrm{x}$ & $\mathrm{x}$ & $\mathrm{x}$ & $\mathrm{x}$ & $\mathrm{x}$ & & & & $\mathrm{x}$ \\
Combustion devices & & & & & & & $\mathrm{x}$ & $\mathrm{x}$ & $\mathrm{x}$ & \\
Nitrogen & $\mathrm{x}$ & $\mathrm{x}$ & $\mathrm{x}$ & $\mathrm{x}$ & $\mathrm{x}$ & $\mathrm{x}$ & $\mathrm{x}$ & $\mathrm{x}$ & $\mathrm{x}$ & $\mathrm{x}$ \\
Feed water & $\mathrm{x}$ & $\mathrm{x}$ & $\mathrm{x}$ & $\mathrm{x}$ & $\mathrm{x}$ & & & $\mathrm{x}$ & & \\
Compressed air & $\mathrm{x}$ & $\mathrm{x}$ & $\mathrm{x}$ & $\mathrm{x}$ & $\mathrm{x}$ & $\mathrm{x}$ & $\mathrm{x}$ & $\mathrm{x}$ & $\mathrm{x}$ & $\mathrm{x}$ \\
Vacuum system & $\mathrm{x}$ & $\mathrm{x}$ & $\mathrm{x}$ & $\mathrm{x}$ & $\mathrm{x}$ & $\mathrm{x}$ & $\mathrm{x}$ & $\mathrm{x}$ & $\mathrm{x}$ & $\mathrm{x}$ \\
\hline
\end{tabular}

The dependence of utilities at site Stenungsund are given by the utility dependence flowchart in figure 2 .

The disturbance limits for disturbances on utilities at site Stenungsund are listed below. These limits have been determined by speaking to operators and other staff at the site and looking into historical databases and log books.

\section{- Steam}

- Pressure in high-pressure steam net below 33 bar - Pressure in high-pressure steam net over 45 bar

- Pressure in middle-pressure steam net below 12 bar

- Cooling water

- Cooling water temperature higher than $27^{\circ} \mathrm{C}$

- Temperature of water cooled by cooling fans in area 1, 2 and 3 higher than $70^{\circ} \mathrm{C}$

- Temperature of water cooled by cooling fan in area 7 higher than $65^{\circ} \mathrm{C}$

- Loss of cooling water flow

- Electricity

- Voltage below $99 \%$ of normal voltage for $40 \mathrm{kV}$ electricity

- Voltage below $99 \%$ of normal voltage for $130 \mathrm{kV}$ electricity

- Loss of low voltage electricity

- Loss of electricity

- Water treatment

- Amount of SUSP in outgoing water more than $4000 \mathrm{~kg}$ a year

- Amount of DOC in outgoing water more than $4000 \mathrm{~kg}$ a year

- Combustion of tail gas

- Flare flame goes out.

- Failure of combustion device at area 7

- Failure of combustion device at area 8

- Failure of combustion device at area 9

- Nitrogen

- Pressure in main nitrogen pipe less than 21 bar

- Water

- Pressure in main feed water pipe less than 20 bar

- Compressed air

- Zero pressure of instrument air

- Vacuum system

- Loss of vacuum system

The time period August 1, 2007 to July 1, 2010 is considered. There has been one planned stop during the time period, from September 15 to October 8, 2009. Data from this time period is not included in the computations.

\subsection{Step 2: Compute utility and area availability}

Availabilities for all utilities can be computed using measurement data. First, all planned stops are removed, then simultaneous faults for dependent utilities, with help from the utility dependence flowchart. In table 2 the resulting utility availabilities at site Stenungsund during the time period August 1, 2007 to July 1, 2010 are listed.

Using measurement data, table 1 and the flowchart of the product flow in figure 3 , the direct and total area availabilities for all production areas can be computed. The resulting area availabilities are listed in table 3 . 
Table 2. Utility availabilities.

\begin{tabular}{lr}
\hline Utility & $\begin{array}{r}\text { Availability } \\
(\%)\end{array}$ \\
\hline Water treatment & 100.00 \\
Vacuum systems & 100.00 \\
Electricity & 99.98 \\
Compressed air & 99.98 \\
Nitrogen & 99.87 \\
Water & 98.99 \\
Steam & 95.94 \\
Combustion of tail gas & 91.72 \\
Cooling water & 89.06 \\
\hline
\end{tabular}

Table 3. Area availabilities.

\begin{tabular}{ccc}
\hline Area & $\begin{array}{c}\text { Direct } \\
\text { availability } \\
(\%)\end{array}$ & $\begin{array}{c}\text { Total } \\
\text { availability } \\
(\%)\end{array}$ \\
\hline 1 & 85.14 & 85.14 \\
2 & 85.14 & 85.14 \\
3 & 85.14 & 85.14 \\
4 & 87.95 & 85.14 \\
5 & 87.95 & 85.14 \\
6 & 87.96 & 85.14 \\
7 & 83.01 & 80.91 \\
8 & 89.74 & 84.39 \\
9 & 84.64 & 82.08 \\
10 & 90.39 & 90.39 \\
\hline
\end{tabular}

\subsection{Results and discussions}

In this case, the calculation of utility availabilities indicates that the cooling water utility has the lowest availability (89 \%). However, this does not necessarily mean that the cooling water utility is the utility that gives rise to the largest revenue loss. The calculation of the area availabilities indicates that area 7 is most affected by utility disturbances, with a direct availability of $83 \%$ and a total availability of $81 \%$. However, this does not necessarily mean that area 7 is the most cumbersome from an economic perspective. To answer the question of which utility that gives rise to the largest revenue loss step 3 of the general method must be completed, for which a model of the site is needed. This has been done for on/off modeling without buffer tanks in Lindholm et al. (2011). A case study where on/off modeling including buffer tanks is applied is currently active. Another comment is that choosing the critical limits for disturbances on utilities is an iterative procedure. After computing availability of all utilities, the result must be reviewed: Are the availabilities reasonable when comparing with the actual production from the specified time period? If maximum production has been achieved during a period where not all utilities were available, the limits might have to be reviewed.

\section{CONCLUSIONS}

In this work, a general method for handling disturbances on utilities is presented. Two important concepts are introduced and defined; Utility availability and area availability. These concepts are of importance in the the method, in which they are used as measures of the operation of utilities and areas. A case study at site Stenungsund at Perstorp $\mathrm{AB}$ is presented to illustrate how the method is applied to an industrial site. Furthermore, different modeling approaches for modeling a production site with respect to utilities are suggested. The model of the site is needed to complete all steps of the method. The modeling approaches are of different level of detail and also give solutions of corresponding level of detail. A simpler approach could be useful for getting a quick view on which utilities that cause the largest revenue losses at a site, whereas a more advanced approach gives better conditions for reducing the revenue loss.

\section{ACKNOWLEDGEMENTS}

The research is performed within the framework of the Process Industrial Centre at Lund University (PIC-LU) supported by the Swedish Foundation for Strategic Research (SSF).

\section{REFERENCES}

Bauer, M., Cox, J.W., Caveness, M.H., Downs, J.J., and Thornhill, N.F. (2007). Nearest neighbors methods for root cause analysis of plantwide disturbances. Ind. Eng. Chem. Res, 46, 5977-5984.

Brennan, D. (1998). Process Industry Economics: An International Perspective. Institution of Chemical Engineers.

Greenberg, H.R. (1991). Risk Assessment and Risk Management for the Chemical Process Industry. John Wiley \& Sons, Inc.

Grossmann, I.E. and Furman, K.C. (2009). Challenges in enterprise wide optimization for the process industries. In Optimization and Logistics Challenges in the Enterprise, volume 30 of Springer Optimization and Its Applications, 3-59. Springer US.

ISA-95.00.01-2000 (2000). Enterprise-Control, System Integration, Part 1: Models and Terminology. ISA95.00.01-2000.

ISO/WD-22400-2 (2009). Manufacturing operations management - Key performance indicators - Part 2: Definitions and descriptions of KPIs. ISO/WD 22400-2.

Lindholm, A. (2011). A method for improving plant availability with respect to buffer tanks. In proceedings of the $31^{\text {st }}$ IASTED International Conference of Modeling, Identification and Control (MIC), Innsbruck, Austria.

Lindholm, A., Carlsson, H., and Johnsson, C. (2011). Estimation of revenue loss due to disturbances on utilities in the process industry. In proceedings of the $22^{\text {nd }}$ Annual Conference of the Production and Operations Management Society (POMS), Reno, Nevada, USA.

Morris, W.T. (1967). On the art of modeling. Management Science, 13(12), 707-717.

Perstorp (2011). URL http: //www . perstorp.com/.

Qin, S. (1998). Control performance monitoring - a review and assessment. Computers and Chemical Engineering, 23, 173-186.

Skogestad, S. (2004). Control structure design for complete chemical plants. Computers and Chemical Engineering, 28, 219-234.

Williams, J.H., Davies, A., and Drake, P. (1994). Condition-based maintenance and machine diagnostics. Chapman \& Hall.

Xia, Q. and Rao, M. (1999). Knowledge architecture and system design for intelligent operation support systems. Expert Systems with Applications, 17, 115-127. 